\title{
Differential gene expression between adult queens and workers in the ant Lasius niger
}

\author{
JOHANNES GRÄFF, ${ }^{*}+$ STEPHANIE JEMIELITY, ${ }^{*}$ JOEL D. PARKER, ${ }^{*} \ddagger$ KAREN M. PARKER* \\ and LAURENT KELLER* \\ *Department of Ecology and Evolution, University of Lausanne, Biophore, CH-1015 Lausanne, Switzerland
}

\begin{abstract}
Ants and other social insects forming large societies are generally characterized by marked reproductive division of labour. Queens largely monopolize reproduction whereas workers have little reproductive potential. In addition, some social insect species show tremendous lifespan differences between the queen and worker caste. Remarkably, queens and workers are usually genotypically identical, meaning that any phenotypic differences between the two castes arise from caste-specific gene expression. Using a combination of differential display, microarrays and reverse Northern blots, we found 16 genes that were differentially expressed between adult queens and workers in the ant Lasius niger, a species with highly pronounced reproductive division of labour and a several-fold lifespan difference between queens and workers. RNA ligase mediated rapid amplification of cDNA ends (RLM-RACE) and gene walking were used to further characterize these genes. On the basis of the molecular function of their nearest homologues, three genes appear to be involved in reproductive division of labour. Another three genes, which were exclusively overexpressed in queens, are possibly involved in the maintenance and repair of the soma, a candidate mechanism for lifespan determination. In-depth functional analyses of these genes are now needed to reveal their exact role.
\end{abstract}

Keywords: ageing, caste-specific gene expression, immune defence, Lasius niger, reproductive division of labour, somatic maintenance

Received 13 May 2006; revision received 25 August 2006; accepted 15 September 2006

\section{Introduction}

The major organizing principle of social insects (ants, termites, as well as some bees and wasps) is reproductive division of labour. One or a few female individuals (the queens) specialize in reproduction, whereas the other females (the workers) mainly fulfil cooperative tasks such as building the nest, collecting nutrients, rearing the young and defending the colony. This organization provides numerous advantages and forms the basis of the tremendous ecological success of social insects, which are found in almost every type of terrestrial habitat and constitute a

cJohannes Gräff and Stephanie Jemielity contributed equally to this work.

Correspondence: Laurent Keller, Fax: +41 2169241 65; E-mail: laurent.keller@unil.ch.

†Present address: Brain Research Institute, University of Zürich/ Swiss Federal Institute of Technology, CH-8057 Zürich, Switzerland $\ddagger$ Present address: School of Biological Sciences, University of Southampton, SO16 7PX Southampton, UK considerable proportion of the animal biomass on earth (Wilson 1971; Hölldobler \& Wilson 1990).

The complexity of this social organization is highly variable in insect societies (e.g. Pamilo 1991; Ross \& Matthews 1991; Keller 1993; Ross \& Keller 1995) and correlates with colony size (Bourke 1999). Taxa with small colonies (e.g. polistine wasps) are generally characterized by a high worker reproductive potential and a low degree of queenworker dimorphism. In contrast, taxa with large colonies (e.g. many ants) typically exhibit a low worker reproductive potential and a high degree of morphological skew between castes. In such cases, task specialization is strongly pronounced and accompanied by a variety of morphological, physiological and behavioural differences between queens and workers. The most spectacular such difference arguably lies in the lifespan discrepancy between these two castes. Queens can live more than 20 years in some ant species (Keller \& Genoud 1997), whereas workers are generally much shorter-lived, their intrinsic (i.e. environment-independent) lifespan being typically tenfold lower. 
The marked phenotypic differences between ant queens and workers make them an interesting system to study the molecular basis of reproduction, lifespan determination and other caste-specific traits. Importantly, except for a few species (Julian et al. 2002; Volny \& Gordon 2002; Helms Cahan \& Keller 2003), queens and workers develop from genetically identical eggs through environment-induced differential gene expression (Wilson 1971; Wheeler 1986; reviewed in Evans \& Wheeler 2001a). Thus, genes involved in caste-specific physiological traits and behaviours should show caste-specific expression patterns. Studies in one wasp and two bee species have identified a first set of genes that are differentially expressed between reproductive and non-reproductive adults (Judice et al. 2004, 2006; Pereboom et al. 2005; Sumner et al. 2006). Another two studies have compared gene expression between queens and workers in the honeybee, but these studies were performed on larvae (Evans \& Wheeler 1999, 2001b).

The aim of this study was to identify genes underlying caste-specific traits by comparing expression patterns between adult queens and workers in an ant species with a marked caste dimorphism. We chose the black garden ant Lasius niger for two reasons. First, queens and workers show extensive reproductive division of labour: although workers do possess functional ovaries (van der Have et al. 1988), queens largely monopolize colony reproduction (Fjerdingstad et al. 2002). Second, L. niger presents one of the most extreme lifespan differences between queens and workers. Queens can live up to 29 years (Hölldobler \& Wilson 1990), whereas workers have a much shorter lifespan, living only 1-2 years even in conditions with low extrinsic mortality.

\section{Materials and methods}

\section{Sample collection}

Ants used in this study were collected on the campus of the University of Lausanne.

\section{Differential display}

Total RNA was extracted from two sets each of entire adult queens (one over 5-year-old from a field colony, one 1year-old raised in the laboratory), adult workers (pools of several individuals of mixed age; one set from a field colony, one set from a laboratory colony) and adult males (two independent pools of several 1-month-old individuals from field colonies) using the Totally RNA Kit (Ambion). After a DNase treatment (Message Clean Kit, GenHunter), two independent differential display (DD) runs were performed for all three castes. 420 DD bands larger than 150 base pairs (bp) that were unique to one or two castes according to both DD runs were extracted from the gels along with 73 equally expressed bands for use as potential controls. They were re-amplified by polymerase chain reaction (PCR), purified on Qiaquick PCR Kit columns (QIAGEN) and cloned into pCR2.1-TOPO plasmid vectors (Invitrogen). To identify multiple transcripts, eight clones per band were digested with RsaI, MspI, and AluI (Invitrogen). All clones with different restriction patterns, 615 in total, were sequenced (ABI3730). Using the Paracel Clustering Package (Paracel), raw sequence data was quality-filtered, checked for vector contamination and clustered in order to detect redundant (i.e. overlapping) sequences.

\section{Microarray construction and clone tracking}

Microarrays representing all high-quality clones (i.e. clones that yielded a single-band PCR product and a good sequence) were printed and post-treated as described in Reymond et al. (2000) with the following modifications: The dried PCR products were resuspended in $8 \mu \mathrm{L} 3 \times$ SSC, $1.5 \mathrm{~m}$ betaine as in Diehl et al. (2001) and the glass slides used for printing were ArrayIt SuperAldehyde Substrates slides (TeleChem). Correct clone transfer from the 96-well PCR plates to the 384-well plates used for printing was verified by sequencing 19 clones on the 384-well plates. In total, the microarrays consisted of 487 DD-derived expressed sequence tags (3'-ESTs), which, according to the clustering analysis, represented 369 putatively different transcripts. Each microarray print-tip group also contained eight positive control spots used for normalization (SpotReport Alien cDNA Array Validation System, Stratagene), as well as the Lasius niger homologues of the potential housekeeping genes ribosomal protein L8 ( $r p l-8$, GenBank Accession no. EE049695) and $\beta$-actin (EE049694). Finally, there were also several types of negative control spots, including spotting solution without DNA, polyA DNA and nonrelated DNA (Alien cDNAs 9 and 10 of the SpotReport Alien cDNA Array Validation System, Stratagene).

\section{Microarray hybridization, scanning and data analysis}

Total RNA from five independent sets of laboratory $L$. niger queens and workers was extracted as above. We excluded males from this experiment because laboratory colonies do not produce males. Queen samples were pools of 24 18-month-old entire queens. Worker samples were pools of over 1000 entire workers of mixed age (ranging from several-day-old to several-month-old) from the 24 colonies matching the queen samples. Each colony was represented in equal proportions. After isolating poly(A)mRNA (Oligotex Midi kit, QIAGEN), 1-2 $\mu \mathrm{g}$ of mRNA were labelled following the aminoallyl-labelling protocol by Hedge et al. (2000) that was slightly adapted. Briefly, mRNA was mixed with $2 \mu \mathrm{L}$ of Oligo d(T) ${ }_{21}$ primers $(2 \mu \mathrm{g} /$ $\mu \mathrm{L}), 1 \mu \mathrm{L}$ of Alien mRNA Spike mix $(0.25 \mathrm{ng} / \mu \mathrm{L}$ Spike 1 , 
$0.2 \mathrm{ng} / \mu \mathrm{L}$ Spike 2, $0.15 \mathrm{ng} / \mu \mathrm{L}$ Spike 3, $0.1 \mathrm{ng} / \mu \mathrm{L}$ Spike 4, $0.05 \mathrm{ng} / \mu \mathrm{L}$ Spike 5, $0.025 \mathrm{ng} / \mu \mathrm{L}$ Spike $6,0.0125 \mathrm{ng} / \mu \mathrm{L}$ Spike 7, $0.00625 \mathrm{ng} / \mu \mathrm{L}$ Spike 8 ), as well as DEPC-treated water to reach a final volume of $16.4 \mu \mathrm{L}$. This mRNA/ primer mix was incubated $10 \mathrm{~min}$ at $70^{\circ} \mathrm{C}$, followed by $5 \mathrm{~min}$ on ice. Reverse transcription was performed for $2 \mathrm{~h}$ at $42{ }^{\circ} \mathrm{C}$ after adding $6 \mu \mathrm{L} 5 \mathrm{x}$ first-strand buffer, $3 \mu \mathrm{L} 0.1 \mathrm{M}$ DTT, $0.6 \mu \mathrm{L}$ 50x aminoallyl-dNTP mix (25 mm dATP, $25 \mathrm{~mm}$ dCTP, 25 mм dGTP, $15 \mathrm{~mm}$ dTTP, $10 \mathrm{~mm}$ aminoallyl dUTP), $2 \mu \mathrm{L}$ RNAse inhibitor ( $15 \mathrm{U} / \mu \mathrm{L}$, Invitrogen) and $2 \mu \mathrm{L}$ SuperScript II reverse transcriptase $(200 \mathrm{U} / \mu \mathrm{L}$, Invitrogen). The RNA was then hydrolized by adding $15 \mu \mathrm{L}$ $0.1 \mathrm{~m} \mathrm{NaOH}$ and incubating for $10 \mathrm{~min}$ at $70^{\circ} \mathrm{C}$. The $\mathrm{pH}$ was neutralized by adding $15 \mu \mathrm{L} 0.1 \mathrm{M} \mathrm{HCl}$.

The aminoallyl cDNA was purified with a modified Qiaquick PCR Purification Kit (QIAGEN) and linked to Cy3 or Cy5 dyes as in Hedge et al. (2000). The combined Cy3 and Cy5 probes were dried and resuspended in $9 \mu \mathrm{L}$ MilliQ water. After adding $1.9 \mu \mathrm{L} 20 x$ SSC, $1.25 \mu \mathrm{L}$ yeast tRNA $(0.2 \mu \mathrm{g} / \mu \mathrm{L})$ and $0.5 \mu \mathrm{L} 10 \%$ SDS, the probe was denatured at $100{ }^{\circ} \mathrm{C}$ for $2 \mathrm{~min}$ and hybridized to the microarray slides at $64^{\circ} \mathrm{C}$ overnight. Excess probe was removed by washing for $2 \times 5 \mathrm{~min}$ in $2 \times$ SSC, $0.1 \%$ SDS, $2 \times 1 \mathrm{~min}$ in $0.2 \times$ SSC, $2 \times 1 \mathrm{~min}$ in $0.1 \times$ SSC at room temperature.

Microarray slides were scanned as in Reymond et al. (2000). To normalize the signal intensity of the two channels, photomultiplier and laser power settings were adjusted such that the signal ratio of the spiked-in controls (Alien mRNA Spikes 1-8) was as close to 1.0 as possible. Images were analysed with IMAGENE version 4.2 (BioDiscovery).

\section{Reverse Northern blot}

A reverse Northern blot was performed to confirm the expression patterns of the 16 ESTs that had shown greater than twofold expression differences on the microarrays. The positive controls used were $r p l-8$ and $\beta$-actin, as well as three unidentified 3'-ESTs (Ln57_4, Lnc66_1 and Lnc49_1). All these controls had shown equal queen and worker expression levels on the microarrays. Candidate ESTs and controls were amplified in a standard PCR. $40 \mu \mathrm{L}$ of the PCR were mixed with $60 \mu \mathrm{LdH}_{2} \mathrm{O}$, denatured for $10 \mathrm{~min}$ at $99^{\circ} \mathrm{C}$ and then quenched on ice. Equal amounts of each PCR- $\mathrm{dH}_{2} \mathrm{O}$ product were transferred on a nylon membrane (Roche) using a dot-blot apparatus (Bethesda Research Laboratories). The membrane was then washed with $5 x$ SSC and UV cross-linked $\left(120 \mathrm{~J} / \mathrm{cm}^{2}\right)$.

The membrane was hybridized to probes made from $2 \mu \mathrm{g}$ of pooled queen and worker poly(A)-mRNA (as described above) using the Chemiluminescent RT Labeling Kit (Applied Biosystems). To assure independency of results, the RNA used originated from nests other than those used for the microarray experiments. Chemiluminescence was detected with DIG detection reagents (Roche) and subsequent exposure to Biomax Films (Kodak). For better visualization, the reverse Northern blot was performed in two parts, one for lowly expressed ESTs and control genes, and one for highly expressed ESTs and control genes.

\section{Sequence analysis}

To find annotated homologues of the differentially expressed L. niger ESTs, we used standard sequence analysis tools. For all ESTs for which no homologue was found initially $(n=12)$, we tried to obtain the full-length sequence by performing $5^{\prime}$ RNA ligase mediated rapid amplification of cDNA ends (5'RLM-RACE) or gene walking. Homology searches were then repeated with the full-length sequence.

Sequences were 'BLASTed' (BLASTX, Altschul et al. 1997) using the standard settings against the nonredundant (nr) database on the EMBnet server (www.ch.embnet.org). Sequences were annotated with the best-matching and best-documented hit (significance at e $<10^{-4}$ ). In addition, they were attributed a molecular function according to the Gene Ontology annotation (2nd level) of the best BLASTx hit. Also, to find homologous ESTs in other species, sequences were submitted to a TBLASTX search against the EST database at NCBI (http:// www.ncbi.nlm.nih.gov) and a Solenopsis invicta fire ant EST database (Wang et al. in preparation). Finally, to test whether these sequences might be noncoding RNAs, they were subjected to a homology search against the non-coding RNA database Rfam (Griffiths-Jones et al. 2005).

\section{5'RLM-RACE and gene walking}

The $5^{\prime}$ cDNA used for this procedure was made from a pool of entire queen and worker total RNA using the $5^{\prime}$ RLM-RACE kit (Ambion). Primers for the differentially expressed 3 '-ESTs were designed using the freeware program GENEFISHER 1.22 (Giegerich et al. 1996). Primer sequences are available upon request. RACE products were amplified as per the manufacturer's instructions, but using AmpliTaq-Gold (5 U/ $\mu \mathrm{L}$, Roche), and an extended initial denaturation time of $9 \mathrm{~min}$. Bands of interest were isolated on $1 \%$ agarose gels, gel-extracted using the Qiaquick Gel Extraction kit (QIAGEN) and cloned into pCR2.1TOPO (Invitrogen). Several clones per gene were screened for the presence of inserts and sequenced (ABI 3730).

Gene walking was performed with the Universal GenomeWalker Kit (BD Biosciences Clontech) following the manufacturer's instructions. Primer sequences are available upon request. Bands of interest were isolated on $1 \%$ agarose gels, gel-purified with the Wizard SV Gel and PCR Clean-Up System (Promega) and cloned using the pGEM-T Easy Vector (Promega). Finally, products were purified (Qiaprep Miniprep Kit, QIAGEN) and sequenced (ABI 3730). 


\section{Data deposition}

All L. niger ESTs sequenced during this study were deposited in GenBank under Accession nos DY543805 to DY544160 and DY676280 to DY676292.

\section{Results}

\section{Differential gene expression between adult queens and workers}

A set of 369 different 3'-ESTs enriched for caste-specific genes was created by differential display and used for printing cDNA microarrays. Among these genes, 16 showed strong (i.e. greater than twofold) expression differences between adult queens and workers in five microarray replicates (Fig. 1; paired $t$-tests without Bonferroni correction: $P<0.05$ in all cases). The remaining genes were either similarly expressed between queens and workers $(P>$ 0.05 ) or yielded too weak a signal to be reliably quantified. Among the 16 differentially expressed ESTs, nine were overexpressed in queens and seven in workers. A reverse Northern blot was in accord with the microarray-deduced expression patterns for these ESTs (Fig. 2).

\section{Gene identification}

We obtained full-length sequences for seven (Ln117_4, Ln150_8, Ln161_1, Ln287_3, Ln322_1, Ln356_2, Ln385_5) out of the 16 differentially expressed ESTs by means of $5^{\prime}$ RLM-RACE. In addition, the sequence of one EST (Ln96_2) could be extended by means of gene walking. BLASTX searches returned significant homologies to annotated

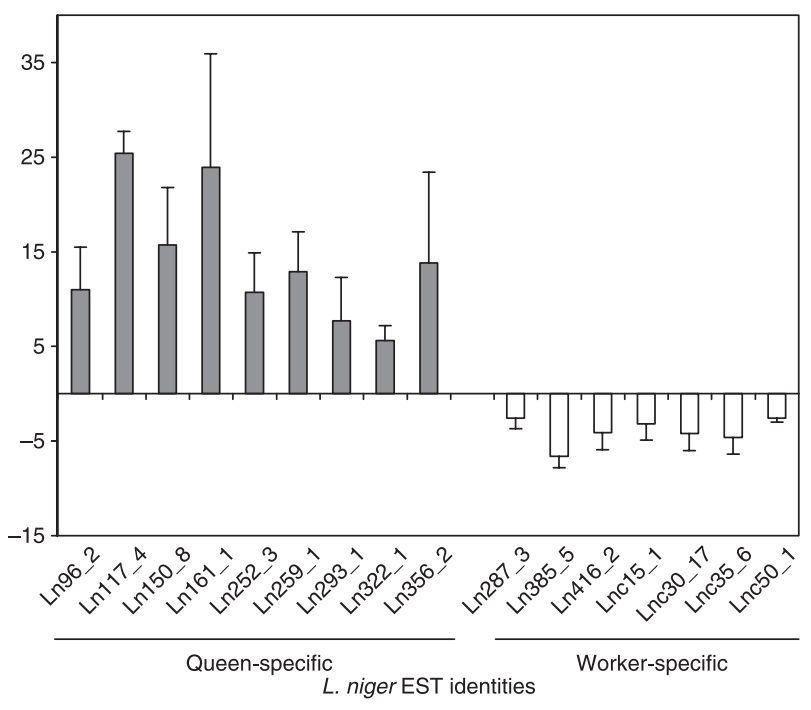

Fig. 1 Microarray analysis of differential gene expression between adult Lasius niger queens and workers. Shown are the mean fold changes and standard deviations of ESTs found to be differentially expressed between queens and workers according to five independent microarray runs $(P<0.05$ for all cases; paired $t$-tests without Bonferroni correction). Fold changes were calculated as queen signal intensity divided by worker signal intensity (black bars) or as worker signal intensity divided by queen signal intensity (open bars).

sequences for six out of the 16 differentially expressed ESTs; and another four ESTs showed significant homologies to sequences of unknown function. These results are summarized in Table 1. The six remaining ESTs did not have any significant homologies to published sequences. Finally, none of the ESTs showed a significant homology to

(a)

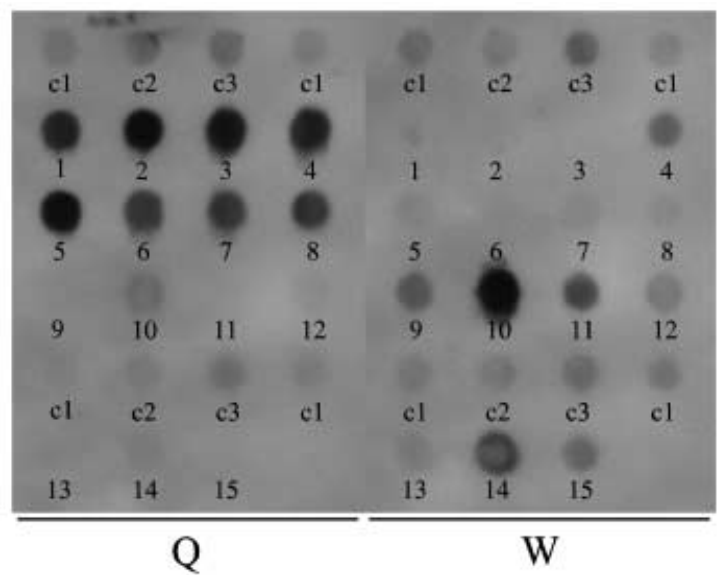

(b)

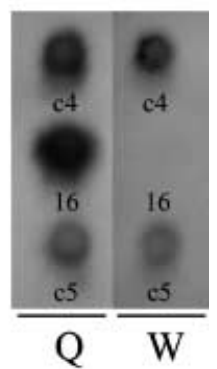

Fig. 2 Reverse Northern blot confirming the microarray-deduced differential gene expression patterns. Depicted are gene expression levels in adult queens (Q) and workers (W) for all ESTs and control genes. For technical reasons (see Materials and methods) the reverse Northern blot was performed in two parts: (a) and (b). 1-8 and 16 show ESTs overexpressed in queens, 9-15 ESTs overexpressed in workers, and c1c5 represent control genes with similar expression levels in the two castes. Legend: 1, Ln117_4; 2, Ln150_8; 3, Ln161_1; 4, Ln252_3; 5, Ln259_1; 6, Ln293_1; 7, Ln322_1; 8, Ln356_2; 9, Ln287_3; 10, Ln385_5; 11, Lnc15_1; 12, Lnc50_1; 13, Lnc30_17; 14, Lnc35_6; 15, Ln416_2; 16, Ln96_2; c1, Ln57_4; c2, Lnc66_1; c3, Lnc49_1; c4, $\beta$-actin; c5, rpl-8. 
Table 1 Differentially expressed Lasius niger ESTs with significant homologies to sequences in public databases. Displayed are the L. niger EST identities (ID), the corresponding GenBank Accession numbers, the length in base pairs (bp), the best-annotated BLAsTx hit of the nonredundant database, the $e$-value (significance at $10^{-4}$ ) of the best-annotated BLAsTx hit, and its gene ontology (GO) annotation. Where existing, the твLASTx hit against the Solenopsis invicta EST database as well as the S. invicta GenBank Accession number and $e$-value (significance at $10^{-4}$ ) are also displayed

\begin{tabular}{|c|c|c|c|c|c|c|c|}
\hline $\begin{array}{l}\text { L. niger } \\
\text { EST ID }\end{array}$ & $\begin{array}{l}\text { GenBank } \\
\text { Accession } \\
\text { no. }\end{array}$ & $\begin{array}{l}\text { Length } \\
\text { (bp) }\end{array}$ & $\begin{array}{l}\text { \% identity match by BLASTx } \\
\text { (UniProt/TrEMBL Accession no.) }\end{array}$ & $e$-value & $\begin{array}{l}\text { Molecular } \\
\text { function (GO) }\end{array}$ & $\begin{array}{l}\text { TBLASTX hit } \\
\text { against } \\
\text { S. invicta }\end{array}$ & $e$-value \\
\hline \multicolumn{8}{|c|}{ ESTs overexpressed in queens } \\
\hline Ln96_2 & DY543805 & 991 & $35 \%$ to Pimpla nipponica vitellogenin (O17428) & $6 \times 10^{-44}$ & Lipid transporter & EE135001 & $2 \times 10^{-11}$ \\
\hline Ln117_4 & DY543806 & 570 & Unknown & NS & Unknown & EE128149 & $3 \times 10^{-8}$ \\
\hline Ln150_8 & DY543807 & 637 & $\begin{array}{l}68 \% \text { to Drosophila melanogaster yellow-g2 } \\
\text { (Q9W028) }\end{array}$ & $9 \times 10^{-20}$ & Hydrolase & - & NS \\
\hline Ln161_1 & DY543808 & 699 & $\begin{array}{l}38 \% \text { to Apis mellifera hypothetical protein } \\
\text { (ENSAPMP00000024385) }\end{array}$ & $8 \times 10^{-6}$ & Unknown & EE138604 & $6 \times 10^{-55}$ \\
\hline Ln252_3 & DY543812 & 439 & $\begin{array}{l}37 \% \text { to Rhodnius prolixus thrombin inhibitor } \\
\text { protein (Q06684) }\end{array}$ & $2 \times 10^{-8}$ & Enzyme inhibitor & - & NS \\
\hline Ln293_1 & DY543813 & 336 & $\begin{array}{l}\text { 100\% to Drosophila melanogaster histone } 2 \mathrm{~A} \\
\text { (P84051) }\end{array}$ & $8 \times 10^{-40}$ & Nucleic acid binding & EE138974 & $9 \times 10^{-47}$ \\
\hline Ln322_1 & DY543809 & 399 & $\begin{array}{l}\text { 42\% to Apis mellifera hypothetical protein } \\
\text { (ENSAPMP00000017984) }\end{array}$ & $1 \times 10^{-12}$ & Unknown & - & NS \\
\hline \multicolumn{8}{|c|}{ ESTs overexpressed in workers } \\
\hline Ln385_5 & DY543811 & 399 & $\begin{array}{l}40 \% \text { to Apis mellifera pheromone-binding } \\
\text { protein ASP1 (Q8WRW5) }\end{array}$ & $3 \times 10^{-5}$ & Odorant binding & EE136374 & $1 \times 10^{-13}$ \\
\hline Lnc30_17 & DY543814 & 325 & Unknown & NS & Unknown & EE135917 & $4 \times 10^{-5}$ \\
\hline Lnc35_6 & DY543815 & 138 & $\begin{array}{l}63 \% \text { to Anopheles gambiae hypothetical } \\
\text { membrane alanyl aminopeptidase (Q7PRZ0) }\end{array}$ & $1 \times 10^{-37}$ & Peptidase & - & NS \\
\hline
\end{tabular}

NS, not significant.

noncoding RNA sequences. Hereafter, we only focus on ESTs with significant homologies (Table 1).

Among the nine ESTs overexpressed in queens, four had annotated homologues in public databases (Ln96_2, Ln150_8, Ln252_3, Ln293_1). The first, Ln96_2, showed significant similarity to the parasitoid wasp Pimpla nipponica vitellogenin, a lipoproteinic yolk precursor produced by all oviparous species (Byrne et al. 1989). The second, Ln150_8, was similar to the fruitfly protein Yellow-g2, a member of the yellow-related Drosophila melanogaster proteins (Maleszka \& Kucharski 2000). The third, Ln252_3, was most similar to the thrombin inhibitor protein Rhodniin, a Kazal-type serine protease inhibitor isolated from the blood-sucking triatomid bug Rhodnius prolixus (Friedrich et al. 1993). Ln252_3 also had several other, hardly less significant BLASTX matches to other arthropod serine protease inhibitors. Finally, the fourth EST, Ln293_1, showed a strong similarity to the D. melanogaster histone 2A, a member of the histone core proteins. Additionally, three queen-specific ESTs showed significant hits to functionally unknown sequences. Two of them (Ln161_1 and Ln322_1) were homologous to functionally unknown Apis mellifera proteins, whereas the third one (Ln117_4) was similar to a functionally unknown Solenopsis invicta EST.
Among the seven ESTs overexpressed in workers, two (Ln385_5 and Lnc35_6) had annotated homologues in public databases. The first, Ln385_5, resembled the A. mellifera pheromone-binding protein ASP1, which is found in the antennae of honeybee drones and workers (Danty et al. 1998). The second, Lnc35_6, was similar to a hypothetical Anopheles gambiae membrane alanyl aminopeptidase. Among the worker-specific ESTs lacking annotated homologues, one (Lnc30_17) was similar to a functionally not characterized S. invicta EST.

\section{Discussion}

Using a combination of differential display, microarray analysis and reverse Northern blot, we isolated 16 ESTs that are differentially expressed between adult Lasius niger queens and workers. Based on the annotation of their homologues in other organisms, three of these genes are potentially involved in reproductive division of labour and three in somatic maintenance. It is, however, important to note that the functions of these genes remain speculative, both because queens and workers differ in a number of traits other than reproductive status and lifespan and, most importantly, because the function of these genes have not been tested experimentally. 
Genes potentially involved in reproductive division of labour

The vitellogenin homologue Ln96_2 is most likely necessary for producing viable eggs. Vitellogenin is a key nutriment for the developing embryo in oviparous species and is secreted by the female fat body just prior to yolk deposition (Haunerland \& Shirk 1995). It is usually produced by the egg-laying caste, but in honeybees and several ant species it can also be produced by non-egg-laying individuals (Engels et al. 1990). In L. niger, vitellogenin was highly overexpressed in queens compared to workers, which is consistent with the fact that queens monopolize oviposition (Fjerdingstad et al. 2002). Similar results were obtained in two other social insect species. In the ant Solenopsis invicta, vitellogenin expression is higher in egg-laying than non egg-laying queens (Tian et al. 2004), and in the wasp Polistes canadensis queens show higher vitellogenin expression levels than workers (Sumner et al. 2006).

The second gene, the yellow-g2 homologue Ln150_8, is probably also important for egg production. Several yellow loci have been discovered in the fruitfly, all of which are highly similar in sequence (Maleszka \& Kucharski 2000). Recently, the yellow-g and yellow-g2 genes were suggested to function in fruitfly oogenesis, based on the grounds that these genes increase in copy number during fruitfly oogenesis and are highly expressed in follicle cells of oocytes (Claycomb et al. 2004). Our finding that yellow- $g 2$ is overexpressed in $L$. niger queens is consistent with a role of yellow-g2 during oogenesis. Similar results were obtained in S. invicta where yellow-g2 is expressed at higher levels in egg-laying queens than in non egg-laying queens (Tian et al. 2004).

The third gene possibly involved in reproductive division of labour, Ln385_5, which encodes a homologue of the pheromone-binding protein ASP1, might play a more complex role. In the honeybee, ASP1 interacts with the major compounds of the queen mandibular gland pheromone and is therefore most likely involved in eliciting the specific behaviours that drones and workers display when exposed to this pheromone (Danty et al. 1999). The honeybee queen mandibular gland pheromone affects the likelihood of workers to undertake certain tasks, such as raising new queens, foraging and initiating swarming, which has far-reaching consequences on colony organization (reviewed in Winston \& Slessor 1992; Pankiw et al. 1998). In addition, this pheromone is thought to be involved in regulating the development of ovaries in workers (reviewed in Wilson 1971; but see Willis et al. 1990) and might therefore help promote reproductive division of labour. In L. niger, the ASP1 homologue was overexpressed in workers, which could be indicative of a role similar to that in bees, where ASP1 is mainly present in worker and drone antennae (Danty et al. 1998).

\section{Genes potentially involved in somatic maintenance}

Three differentially-expressed L. niger genes might be involved in the maintenance and repair of the soma. Such genes have been designated as candidates for controlling longevity (Kirkwood 2005). Intriguingly, we found all of these genes to be overexpressed in the longer-lived queens.

The vitellogenin homologue Ln96_2 is, besides its aforementioned function in reproduction, likely to also affect somatic maintenance since such a role has been demonstrated for honeybee vitellogenin. Amdam et al. (2004) showed that hive bees, i.e. workers that perform in-hive tasks and have a slow ageing rate, have increased vitellogenin levels compared to forager bees which age at a much faster speed. Moreover, experimental evidence suggests that low vitellogenin titres cause a decrease in the number of functional haemocytes (Amdam et al. 2004; Seehuus et al. 2006), which are essential components of the honeybee immune system (reviewed in Rolff \& Siva-Jothy 2003). Thus, the higher levels of vitellogenin in hive bees might reflect an increased investment in somatic maintenance and is thought to be one of the causes for the decreased ageing rate of this type of bees (Amdam et al. 2004; Seehuus et al. 2006). The higher vitellogenin expression level in the longer-lived L. niger queens is consistent with this interpretation.

The second gene, Ln252_3, encodes a serine proteinase inhibitor homologue. Arthropod haemolymph contains high concentrations of several types of serine proteinase inhibitors (Polanowski \& Wilusz 1996), most of which are thought to function in immune responses (reviewed in Kanost 1999). In adult arthropods, these enzymes have been shown to serve as a direct defence against microbial proteinases and to control proteolytic cascades that lead to haemolymph coagulation and melanization after wounding or infection (reviewed in Kanost 1999). The finding that the L. niger proteinase inhibitor homologue is highly overexpressed in queens compared to workers could indicate that the longer-lived queens invest more in their immune defence than the shorter-lived workers.

The third gene, Ln293_1, encodes a histone 2A (H2A) homologue. $\mathrm{H} 2 \mathrm{~A}$ is best known for its structural role within chromatin, but recent studies suggest that this protein also plays an evolutionarily conserved role in innate immune defence (e.g. Augusto et al. 2003; Patat et al. 2004). Peptides cleaved from H2A show antimicrobial properties in the skin mucosa of a variety of fish species (Park et al. 1998; Cho et al. 2002; Fernandes et al. 2002). Furthermore, $\mathrm{H} 2 \mathrm{~A}$ and another histone have been suggested to play a role in shrimp immune defence (Patat et al. 2004) and to be responsible for extra-cellular bacteria killing through neutrophils in mammals (Brinkmann et al. 2004). Since histones are among the best-conserved proteins in eucaryotes (e.g. Pehrson \& Fuji 1998), it appears probable that they do 
not vary significantly in function between species. It is therefore plausible that the overexpression of the $\mathrm{H} 2 \mathrm{~A}$ homologue in $L$. niger queens could reflect an increased investment in immune defence, and thus somatic maintenance. Alternatively, the overexpression of $\mathrm{H} 2 \mathrm{~A}$ in queens might simply be due to a high rate of cell division in this caste.

\section{Other genes}

Several other genes discovered in this study were of unclear function. Lnc35_6, which is overexpressed in workers, encodes a hypothetical membrane alanyl aminopeptidase. Members of this protein family have been shown to be involved in insect pathogenesis after bacterial infection. In a variety of insects, membrane alanyl aminopeptidases are putative receptors for toxins of the bacterium Bacillus thuringiensis (Naimov et al. 2001, Gill \& Ellar 2002; Herrero et al. 2005). Binding of these toxins to membrane alanyl aminopeptidases mediates $B$. thuringiensis' toxicity in some species (e.g. Rajagopal et al. 2002), whereas in others it does not (e.g. Banks et al. 2003). B. thuringiensis also attack ants (Pinto et al. 2003), but whether the bacterial toxins bind to ant membrane alanyl aminopeptidases has not yet been investigated.

Four other L. niger genes (Ln117_4, Ln161_1, Ln322_1 and Lnc30_17) had only significant homologues to functionally unknown sequences.

\section{Comparison with similar studies}

The genes found to be differentially expressed between L. niger queens and workers hardly overlapped with genes differentially expressed between adult queens and workers of other social insects. Similar studies in the bumblebee Bombus terrestris (Pereboom et al. 2005), in the stingless bee Melipona quadrifasciata (Judice et al. 2004, 2006) and in the primitively eusocial was $P$. canadensis (Sumner et al. 2006) have identified close to 50 genes with expression differences between adult queens and workers. But only one of these genes, the Polistes vitellogenin homologue, figured also among the L. niger differentially expressed genes. It is thus possible that caste-specific traits are governed by different sets of genes in different species. Alternatively, the lack of overlap might simply be due to the small number of differentially expressed genes surveyed in each study.

The finding that a considerable number of differentially expressed L. niger ESTs (six out of 16) had no homologues in public databases is in accordance with similar results in another ant species (Goodisman et al. 2005) and has several plausible reasons. Most L. niger sequences that failed to have significant homologues were relatively short or lacked long open reading frames (data not shown). This suggests that they might be $3^{\prime}$ untranslated regions, which are generally not conserved in sequence. Alternatively, they may represent non-coding RNAs, which are also often poorly conserved among species (Mattick 2005). In both cases, the lack of conservation renders the prediction of function based on sequence comparison difficult. This situation is further complicated by the fact that no social insect genome has been fully annotated so far. As a consequence, genomic studies on social insects will remain limited until annotation and functional analyses have gained ground.

\section{Conclusion}

In conclusion, this study found several genes with queenworker expression differences that are potentially involved in reproductive division of labour, in somatic maintenance mechanisms and in other processes. Intriguingly, the genes that possibly promote somatic maintenance are all linked to immune defence and exclusively overexpressed in queens. Whether these genes indeed contribute to the long lifespan of L. niger queens remains, however, to be demonstrated. A next step will be to assess the exact expression patterns of candidate genes with in situ hybridizations, which should reduce the number of possible functions for these genes. But ultimately, only genetic manipulations or RNA interference will make it possible to assess the exact function of these genes. Hopefully, these techniques will soon be available for ants.

\section{Acknowledgements}

We would like to thank P. Reymond, L. Falquet and P. Uva for technical help with microarray and bioinformatics analyses, $\mathrm{R}$. Schöb who gladly helped with the figures, as well as R. Hammond, J. Gunz and three anonymous referees for their comments on earlier versions of this manuscript. This work was funded by grants from the Swiss National Science Foundation, AETAS Foundation for Research into Ageing (Geneva), the A.R. \& J. Leenards Foundation (Lausanne) and a special genomic grant by the Rectorate of the University of Lausanne.

\section{References}

Altschul SF, Madden TL, Schaffer AA et al. (1997) Gapped BLAST and PSI-BLAST: a new generation of protein database search programs. Nucleic Acids Research, 25, 3389-3402.

Amdam GV, Simoes ZLP, Hagen A et al. (2004) Hormonal control of the yolk precursor vitellogenin regulates immune function and longevity in honeybees. Experimental Gerontology, 39, 767773.

Augusto LA, Decottignies P, Synguelakis M et al. (2003) Histones: a novel class of lipopolysaccharide-binding molecules. Biochemistry, 42, 3929-3938.

Banks DJ, Hua G, Adang M (2003) Cloning of a Heliothis virescens $110 \mathrm{kDa}$ aminopeptidase N and expression in Drosophila S2 cells. Insect Biochemistry and Molecular Biology, 33, 499-508. 
Bourke AFG (1999) Colony size, social complexity and reproductive conflict in social insects. Journal of Evolutionary Biology, 12, 245-257.

Brinkmann V, Reichard U, Goosmann C et al. (2004) Neutrophil extracellular traps kill bacteria. Science, 303, 1532-1535.

Byrne BM, Gruber M, Ab G (1989) The evolution of egg-yolk proteins. Progress in Biophysics and Molecular Biology, 53, 33-69.

Cho JH, Park IY, Kim HS et al. (2002) Cathepsin D produces antimicrobial peptide parasin I from histone $\mathrm{H} 2 \mathrm{~A}$ in the skin mucosa of fish. FASEB Journal, 16, 429-431.

Claycomb JM, Benasutti M, Bosco G, Fenger DD, Orr-Weaver TL (2004) Gene amplification as a development strategy: isolation of two developmental amplicons in Drosophila. Developmental Cell, 6, 145-155.

Danty E, Arnold G, Huet JC et al. (1998) Separation, characterization and sexual heterogeneity of multiple putative odorant-binding proteins in the honeybee Apis mellifera L. (Hymenoptera: Apidea). Chemical Senses, 23, 83-91.

Danty E, Briand L, Michard-Vanhee C et al. (1999) Cloning and expression of a queen pheromone-binding protein in the honeybee: an olfactory-specific, developmentally regulated protein. Journal of Neuroscience, 19, 7468-7475.

Diehl F, Grahlmann S, Beier M, Hoheisel JD (2001) Manufacturing DNA microarrays of high spot homogeneity and reduced background signal. Nucleic Acids Research, 29, e38.

Engels WKH, Zillikens A, Simoes ZLP et al. (1990) Honey bee reproduction: vitellogenin and caste-specific regulation of fertility. Advances in Invertebrate Reproduction, 5, 445-452.

Evans JD, Wheeler DE (1999) Differential gene expression between developing queens and workers in the honey bee, Apis mellifera. Proceedings of the National Academy of Sciences, USA, 96, $5575-5580$.

Evans JD, Wheeler DE (2001a) Gene expression and the evolution of insect polyphenisms. Bioessays, 23, 62-68.

Evans JD, Wheeler DE (2001b) Expression profiles during honeybee caste determination. Genome Biology, 2, 0001.1-0001.6.

Fernandes JMO, Kemp GD, Molle MG, Smith VJ (2002) Antimicrobial properties of histone H2A from skin secretions of rainbow trout, Oncorhynchus mykiss. Biochemical Journal, 368, 611-620.

Fjerdingstad EJ, Gertsch PJ, Keller L (2002) Why do some social insect queens mate with several males? Testing the sex-ratio manipulation hypothesis in Lasius niger. Evolution, 56, 553-562.

Friedrich T, Kröger B, Bialojan S et al. (1993) A kazal-type inhibitor with thrombin specificity from Rhodnius prolixus. Journal of Biological Chemistry, 268, 16216-16222.

Giegerich R, Meyer F, Schleiermacher C (1996) GENEFISHER software support for the detection of postulated genes. In: Proceedings of the Fourth International Conference on Intelligent Systems for Molecular Biology. AAAI Press, Menlo Park, California.

Gill M, Ellar D (2002) Transgenic Drosophila reveals a functional in vivo receptor for the Bacillus thuringiensis toxin Cry1Ac1. Insect Molecular Biology, 11, 619-625.

Goodisman MAD, Isoe J, Wheeler DE, Wells MA (2005) Evolution of insect metamorphosis: a microarray-based study of larval and adult gene expression in the ant Camponotus festinatus. Evolution, 59, 858-870.

Griffiths-Jones S, Moxon S, Marshall Met al. (2005) Rfam: annotating non-coding RNAs in complete genomes. Nucleic Acids Research, 33, D121-D124.

Haunerland NH, Shirk PD (1995) Regional and functional differ- entiation in the insect fat-body. Annual Review of Entomology, 40, 121-145.

van der Have TM, Boomsma JJ, Menken SBJ (1988) Sex-investment ratios and relatedness in the monogynous ant Lasius niger (L.). Evolution, 42, 160-172.

Hedge P, Qi R, Abernathy Ket al. (2000) A concise guide to cDNA microarray analysis. BioTechniques, 29, 548-562.

Helms Cahan SH, Keller L (2003) Complex hybrid origin of genetic caste determination in harvester ants. Nature, 424, 306-309.

Herrero S, Gechev T, Bakker PL, Moar WJ, de Maagd RA (2005) Bacillus thuringiensis Cry1Ca-resistant Spodoptera exigua lacks expression of one of four Aminopeptidase $\mathrm{N}$ genes. BMC Genomics 6.

Hölldobler B, Wilson EO (1990) The Ants. Springer, Berlin.

Judice C, Carazzole MF, Festa F, Sogayar MC, Hartfelder K, Pereira GAG (2006) Gene expression profiles underlying alternative caste phenotypes in a highly eusocial bee, Melipona quadrifasciata. Insect Molecular Biology, 15, 33-44.

Judice C, Hartfelder K, Pereira GAG (2004) Caste-specific gene expression in the stingless bee Melipona quadrifasciata - Are there common patterns in highly eusocial bees? Insectes Sociaux, 51, 352-358.

Julian GE, Fewell JH, Gadau J, Johnson RA, Larrabee D (2002) Genetic determination of the queen caste in an ant hybrid zone. Proceedings of the National Academy of Sciences, USA, 99, 8157-8160.

Kanost MR (1999) Serine proteinase inhibitors in arthropod immunity. Developmental and Comparative Immunology, 23, 291-301.

Keller L (1993) Queen Number and Sociality in Insects. Oxford University Press, Oxford, UK.

Keller L, Genoud M (1997) Extraordinary lifespans in ants: a test of evolutionary theories of ageing. Nature, 389, 958-960.

Kirkwood TBL (2005) Understanding the odd science of aging. Cell, 120, 437-447.

Maleszka R, Kucharski R (2000) Analysis of Drosophila yellow-B cDNA reveals a new family of proteins related to the royal jelly proteins in the honeybee and to an orphan protein in an unusual bacterium Deinococcus radiodurans. Biochemical and Biophysical Research Communications, 270, 773-776.

Mattick JS (2005) The functional genomics of noncoding RNA. Science, 309, 1527-1528.

Naimov S, Weemen-Hendriks M, Dukiandjiev S, de Maagd RA (2001) Bacillus thuringiensis delta-endotoxin Cry1 hybrid proteins with increased activity against the Colorado potato beetle. Applied and Environmental Microbiology, 67, 5328-5330.

Pamilo P (1991) Evolution of colony characteristics in social insects. 1. Sex allocation. American Naturalist, 137, 83-107.

Pankiw T, Huang ZY, Winston ML, Robinson GE (1998) Queen mandibular gland pheromone influences worker honey bee (Apis mellifera L.) foraging ontogeny and juvenile hormone titers. Journal of Insect Physiology, 44, 685-692.

Park IY, Park CB, Kim MS, Kim SC (1998) Parasin I, an antimicrobial peptide derived from histone $\mathrm{H} 2 \mathrm{~A}$ in the catfish, Parasilurus asotus. FEBS Letters, 437, 258-262.

Patat SA, Carnegie RB, Kingsbury C et al. (2004) Antimicrobial activity of histones from hemocytes of the Pacific white shrimp. European Journal of Biochemistry, 271, 4825-4833.

Pehrson JR, Fuji RN (1998) Evolutionary conservation of histone macroH2A subtypes and domains. Nucleic Acids Research, 26, 2837-2842.

Pereboom JJM, Jordan WC, Sumner S, Hammond RL, Bourke AFG (2005) Differential gene expression in queen-worker caste 
determination in bumble-bees. Proceedings of the Royal Society of London. Series B, Biological Sciences, 272, 1145-1152.

Pinto LMN, Azambuja AO, Diehl E, Fiuza LM (2003) Pathogenicity of Bacillus thuringiensis isolated from two species of Agromyrmex (Hymenoptera, Formicidae). Brazilian Journal of Biology, 63, 301306.

Polanowski A, Wilusz T (1996) Serine proteinase inhibitors from insect hemolymph. Acta Biochimica Polonica, 43, 445-453.

Rajagopal R, Sivakumar S, Agrawal N, Malhotra P, Bhatnagar RK (2002) Silencing of midgut aminopeptidase N of Spodoptera litura by double-stranded RNA establishes its role as Bacillus thuringiensis toxin receptor. Journal of Biological Chemistry, 277, 46849-46851.

Reymond P, Weber H, Damond M, Farmer EE (2000) Differential gene expression in response to mechanical wounding and insect feeding in Arabidopsis. Plant Cell, 12, 707-719.

Rolff J, Siva-Jothy MT (2003) Invertebrate ecological immunology. Science, 301, 472-475.

Ross KG, Keller L (1995) Ecology and evolution of social organization - insights from fire ants and other highly eusocial insects. Annual Review of Ecology and Systematics, 26, 631-656.

Ross KG, Matthews RW (1991) The Social Biology of Wasps. Cornell University Press, Ithaca, New York.

Seehuus S-C, Norberg A, Gimsa U, Krekling T, Amdam GV (2006) Reproductive protein protects functionally sterile honey bee workers from oxidative stress. Proceedings of the National Academy of Sciences of the United States of America, 103, 962-967.

Sumner S, Pereboom JJM, Jordan WC (2006) Differential gene expression and phenotypic plasticity in behavioural castes of the primitively eusocial wasp, Polistes canadensis. Proceedings of the Royal Society of London. Series B, Biological Sciences, 273, 19-26.

Tian HS, Vinson SB, Coates CJ (2004) Differential gene expression between alate and dealate queens in the red imported fire ant, Solenopsis invicta Buren (Hymenoptera: Formicidae). Insect Biochemistry and Molecular Biology, 34, 937-949.

Volny VP, Gordon DM (2002) Genetic basis for queen-worker dimorphism in a social insect. Proceedings of the National Academy of Sciences, USA, 99, 6108-6111.

Wheeler DE (1986) Developmental and physiological determinants of caste in social Hymenoptera - evolutionary implications. American Naturalist, 128, 13-34.

Willis LG, Winston ML, Slessor KN (1990) Queen honey-bee mandibular pheromone does not affect worker ovary development. Canadian Entomologist, 122, 1093-1099.

Wilson EO (1971) The Insect Societies. Belknap Press, Cambridge, Massachusetts.

Winston ML, Slessor KN (1992) The essence of royalty — honeybee queen pheromone. American Scientist, 80, 374-385.

This work was part of J. Graff's M.Sc. and S. Jemielity's PhD thesis under the supervision of L. Keller. The Keller laboratory uses ants as a model system to study sex allocation, reproductive skew, caste determination and inter-caste differences in ageing in social insects. 